\title{
Application of E-Learning Assessment Based on AHP-BP Algorithm in the Cloud Computing Teaching Platform
}

\author{
http://dx.doi.org/10.3991/ijet.v11i08.6039 \\ Chuanfu $\mathrm{Hu}$ \\ Dongguan University of Technology, Dongguan, Guangdong, China
}

\begin{abstract}
With the increasing development of the Internet, students began to learn quickly through information technology and Internet technology. E-learning is not only an important part of China's higher education, but also is an important means to improve the quality of education, expand the scale of education, deepen educational reform, and realize the educational equity among different classes in society. However, the problem of E-learning is becoming increasingly obvious, which is how to ensure students' effective learning, an important topic in the field of online education. In order to solve this problem, we first build an Elearning platform based on cloud computing, and introduce the software interface and function. The platform is different from the traditional teaching platform, having a strong interaction. Secondly, the data mining technology is used to analyze and collect the record data in the process of $E$ learning, so as to establish the evaluation system of the $E$ learning comprehensive capability. Then, we propose an $\mathrm{E}$ learning ability evaluation model based on an AHP-BP neural network algorithm. We use a BP neural network to predict the evaluation results of 1000 students, and compare them with the results obtained by the AHP method, so as to illustrate the effectiveness of the method proposed in this article. Finally, through experiments we can see that the prediction results of the BP neural network and the evaluation results obtained by the AHP method are similar. This proves the effectiveness of the AHP method on the evaluation of the E-learning comprehensive capability. At the same time, the BP neural network method can be used to deal with a large number of evaluation results, which can save time, without losing accuracy.
\end{abstract}

Index Terms-Cloud computing; E-learning; AHP-BP algorithm; Assessment

\section{INTRODUCTION}

With the increasing development of the Internet, students began to learn quickly through information technology and Internet technology. E-learning is not only an important part of China's higher education, but also an important means to improve the quality of education, expand the scale of education, deepen educational reform, and realize the educational equity among different classes in society. However, the problem of E-learning is becoming increasingly obvious, which is how to ensure students' effective learning, an important topic in the field of online education.

Globally, scholars have conducted much research in the field of online education. Moore [1] proposes a method to motivate learners though various forms of online interactive activities, so as to effectively reduce the learner's sense of distance and separateness. Hiltz [2] believes that various kinds of interactive activities are the key factors of students in E-learning. Gunawardena [3] thinks that the interactive level directly affects the effectiveness of online learning. Karel [4] emphasizes that social interactive play as an important role in the field of E-learning. Chen Li [5] establishes the AHP model of online interactive teaching. According to the definition, significance and methods of the research, Zhong Zhixian [6-9] puts forward five important elements of E-learning; teachers, learners, curriculum, technology and activities. Cao Liangliang [10] uses the social network analysis method to carry out a systematic analysis of the interaction model and data structure of E-learning. According to the characteristics of the dialogue, participation, support and control of E-learning, literature [11] divides the E-learning into four types, each in detail. Zhou Yanan [12] discusses the integration of Elearning and view of knowledge and studying. With the computer and network technology, Gao Xingyuan [13] establishes the E-learning analysis system, and makes a systematic evaluation of students and teaching resources. In view of the learning goals, leadership style, and activity mechanism of virtual class management, Zhang Lixin [14] presents virtual class management strategies.

In the field of online education, learning behavior of learners is a kind of autonomous learning, characterized by a high level of randomness. Therefore, the online communication and simple tests have been unable to accurately evaluate the learning behaviors and learning outcomes. There is an urgent need to explore the online evaluation model for distance learning behavior, so as to ensure that the online teaching can be accurately monitored. There have been many methods to assess the E-learning, such as the data envelopment analysis method, fuzzy comprehensive evaluation method, AHP (analytic hierarchy process) model, grey correlation evaluation method and TOPSIS method $[15,16]$. However, the limitations of various methods will affect the final evaluation results. So, according to the characteristics of online education, and combining the advantages of various evaluation methods, a new method of comprehensive evaluation is needed.

To sum up, in order to solve this problem, we first build an E-learning platform based on cloud computing, and introduce the software interface and function. The platform is different from the traditional teaching platform, having a strong interaction. Secondly, the data mining technology is used to analyze and collect the record data 
in the process of E-learning, so as to establish the evaluation system of the E-learning comprehensive capability. Then, we propose an E-learning capability evaluation model based on AHP-BP neural network algorithm. We use BP neural network to predict the evaluation results of 1000 students, and compare them with the results obtained by the AHP method, so as to illustrate the effectiveness of the method proposed in this article. Finally, through experiments we can see that the prediction results of the BP neural network and the evaluation results obtained by the AHP method are similar. This proves the effectiveness of the AHP method on the evaluation of the E-learning comprehensive capability. At the same time, the BP neural network method can be used to deal with a large number of evaluation results, which can save time without loss of accuracy.

\section{Cloud COMPuting AND E-LEARNING}

The traditional multimedia network classroom is usually comprised of a projector and the hardware network system. However, the consumption, maintenance and upgrades of hardware is problematic and costly for the school. The use of E-learning interactive software based on cloud computing can completely avoid these problems. With the help of this software, Power Point, CD, experimental demonstration system and the teaching methods can be realized with the modern interactive teaching mode of voice, image, text, and animation. The application interface of the E-learning platform is shown in Figure 1.

In the internal interactive software, there is an Elearning interactive platform based on cloud computing. That is to say, the interactive software is in the application layer of the interaction platform. The E-learning platform is a supplement to the traditional mode of education. In addition, it is the inheritance and development of the traditional education mode. The platform includes the following modules:

\section{A. The user registration and login}

Users register in the system through their ID. At the same time, the users must give their name and gender which is used in the E-learning platform. Through the system validation, the user becomes a legitimate user.
Then, the user can log on the E-learning platform, query the resources, and learning the related courses.

\section{B. The data download}

The related resources are uploaded to the server by the resource provider. Students can download the necessary resources and share them with other nodes. This strategy of resource download can give the network good scalability, and also reduce server load and server bottleneck.

\section{The online test}

The E-learning platform includes an online test module, and the test paper is stored in the server and teachers node. According to the account permissions settings, students cannot download their test paper to a local computer, so it can only be completed online. Through the students interface, they finish the test within the specified time, and submit the test paper to the server. Then, the test results will be sent to the clients.

\section{The online discussion}

Teachers and students can use the form of text or voice to exchange their views, so as to achieve real-time interaction.

The E-learning interactive platform with cloud computing is shown in Figure 2.

\section{BASIC KNOWLEDGE Of ASSESSMENT MODEL}

In the field of E-learning, students' learning behavior is more expressed as a kind of autonomous learning with a high level of randomness and one-sided tendency. Therefore, it has been unable to accurately assess the learning behavior and learning outcomes of students through the simple online communication and testing. E-learning is urgently needs to explore a more suitable evaluation model, so as to ensure that the E-learning can accurately monitor and timely guide students to learn. Learning assessment can confirm the students' learning progress, master the learning level, and monitor the learning behavior. Therefore, it provides the decision-making basis for the adjustment and control of the teaching process. It is divided into diagnostic evaluation, formative evaluation and summary evaluation. Next, we introduce the AHP method based on the BP neural network comprehensive evaluation model.

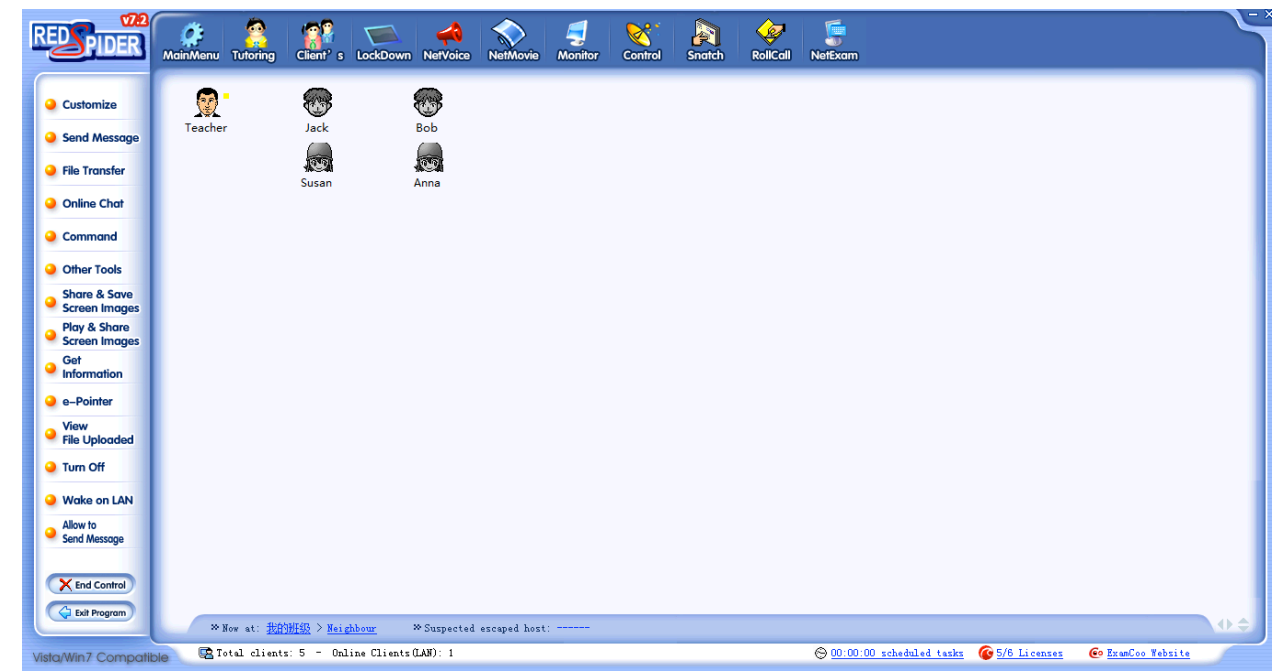

Figure 1. The application interface of E-learning interactive software 


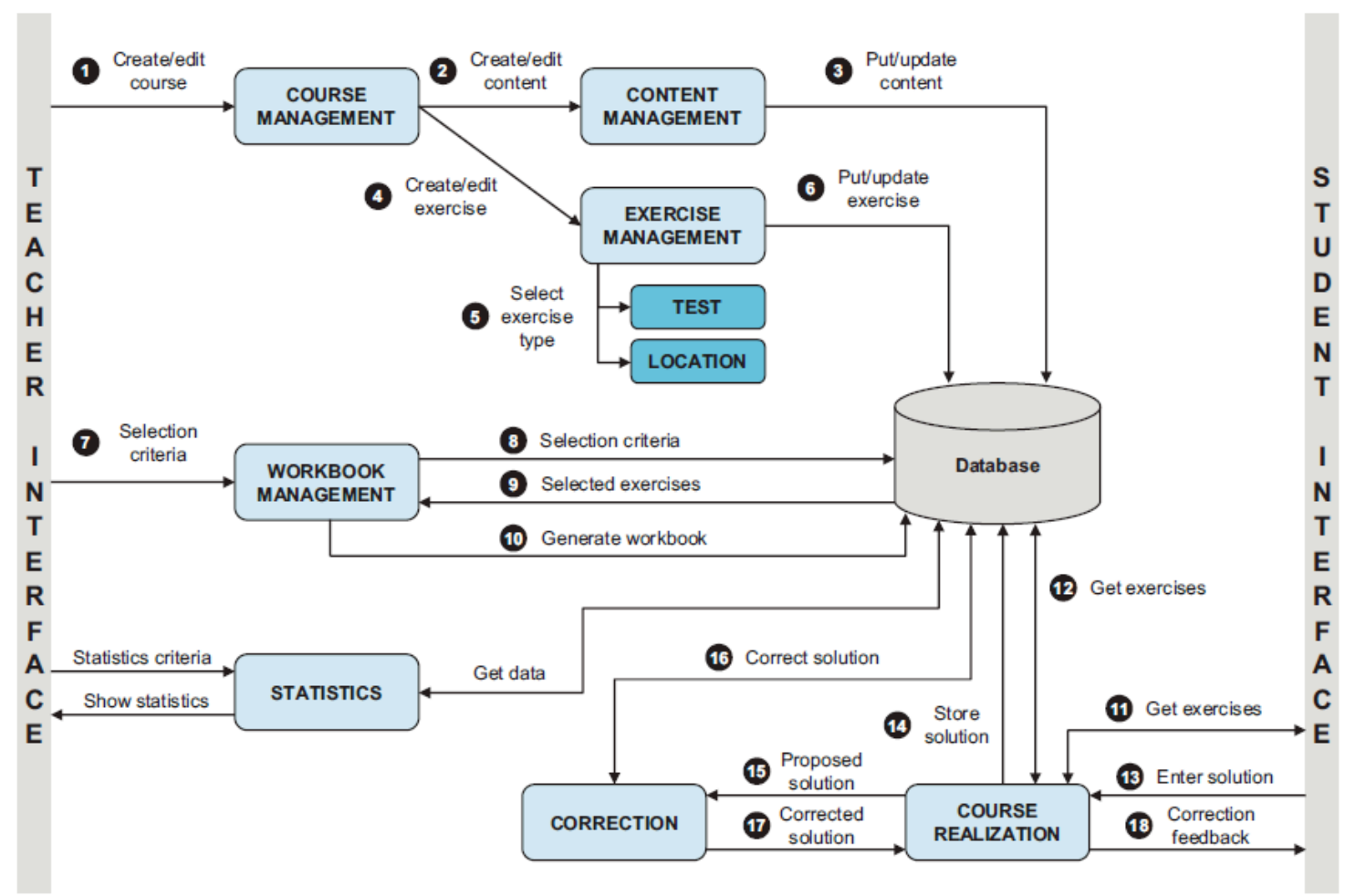

Figure 2. E-learning interactive platform with cloud computing

\section{A. AHP model}

The analytic hierarchy process (AHP) is a simple, flexible and practical multi-objective decision method, which combines both qualitative and quantitative calculation. It adjusts the present optimization method, which can only be used in the quantitative analysis, and makes a quantitative analysis of the non-quantitative problems. On the whole, AHP provides three research methods; the system hierarchy analysis method, 1-9 scale method, and the feature vector method for ranking weights. The steps and applications of AHP are modeled as follows:

Step 1: According to the scaling theory, structuring the multiple comparison judgment matrix is denoted as $A$.

$$
A=\left(a_{i j}\right)_{n \times n} \quad(i=1,2, \mathrm{~L}, n), a_{i j}=1, a_{i j}=1 / a_{j i}
$$

Step 2: The judgment matrix $A$ is normalized:

$$
a_{i j}=a_{i j} / \sum_{k=1}^{n} a_{k j} \quad(i=1,2, \mathrm{~L}, n)
$$

Step 3: Calculate the sum of each row of the judgment matrix:

$$
\omega_{i}=\sum_{j=1}^{n} a_{i j} \quad(i=1,2, \mathrm{~L}, n)
$$

Step 4: The $\omega_{i}$ is normalized:

$$
\omega_{i}=\omega_{i} / \sum_{i=1}^{n} \omega_{i} \quad(i=1,2, \mathrm{~L}, n)
$$

Step 5: According to $A \omega=\lambda_{\max } \omega$, the maximum characteristic root and characteristic vector are calculated. Step 6: Consistency check.

\section{B. BP neural network}

The Sigmoid function is used as the activation function of the hidden nodes of the BP neural network. The activation function of the output node of the BP neural network is different depending on the purpose of the application. If the BP network is used for classification, the output layer node generally uses the sigmoid function or hyperbolic tangent function. Otherwise, if it is used for function approximation, the output layer node uses a linear function. Figure 3 shows a BP network structure with two hidden layers.

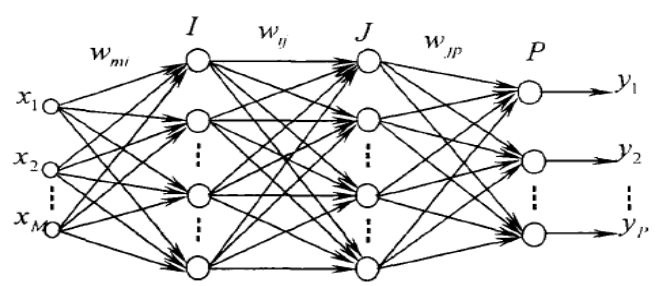

Figure 3. The BP network structure with two hidden layers

The input layer has $M$ input signals, and any one of the input signals is expressed by $m$. The first hidden layer is $I$, that is to say, there are I neurons, and any one of them is expressed by $i$. The second hidden layer is $J$, that is to say, there are $J$ neurons, and any one of them is expressed by $J$ The output layer is $P$, that is to say, there are $P$ neurons, and any one of them is expressed by $P$. The connection weights of the input layer and the first hidden layer are expressed by $w_{m i}$. The connection weights of the first hidden layer and the second hidden layer are expressed by $w_{i j}$, and the connection weights of the second hidden layer and the output layer are expressed by $w_{i p}$. The comprehensive evaluation process of the AHP-BP neural network algorithm is shown in Figure 4. 


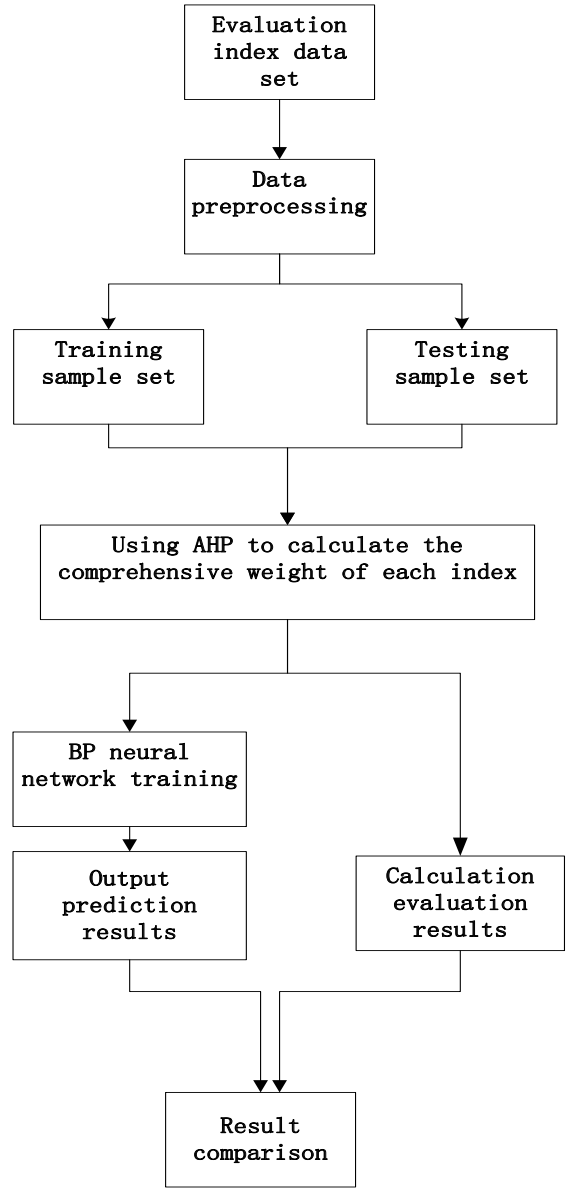

Figure 4. The comprehensive evaluation process of the AHP-BP neural network algorithm

TABLE I.

The EVALUATION INDEX SYSTEM OF E-LEARNING COMPREHENSIVE CAPABILITY

\begin{tabular}{|c|c|c|c|}
\hline $\begin{array}{l}\text { First level } \\
\text { index } F\end{array}$ & $\begin{array}{l}\text { Second level } \\
\text { index } C\end{array}$ & Third level index $B$ & Variable \\
\hline \multirow{12}{*}{$\begin{array}{c}\text { E-learning } \\
\text { comprehen- } \\
\text { sive capability }\end{array}$} & \multirow{3}{*}{$\begin{array}{l}\text { Learning } \\
\text { attitude }\end{array}$} & Interest in learning & $\mathrm{X} 1$ \\
\hline & & The seriousness of learning & $\mathrm{X} 2$ \\
\hline & & Learning efficiency & $\mathrm{X} 3$ \\
\hline & \multirow{3}{*}{$\begin{array}{c}\text { Capability of } \\
\text { actively } \\
\text { participate }\end{array}$} & Ability of solve problems & $\mathrm{X} 4$ \\
\hline & & Number of put questions & $\mathrm{X} 5$ \\
\hline & & Number of uploaded files & $\mathrm{X} 6$ \\
\hline & \multirow{3}{*}{$\begin{array}{l}\text { The use of E- } \\
\text { learning } \\
\text { platform }\end{array}$} & Landing frequency & $\mathrm{X} 7$ \\
\hline & & Total browsing time & $\mathrm{X} 8$ \\
\hline & & Number of job submission & $\mathrm{X} 9$ \\
\hline & \multirow{3}{*}{$\begin{array}{l}\text { Capability of } \\
\text { cooperative } \\
\text { learning }\end{array}$} & $\begin{array}{l}\text { The number of participate in } \\
\text { the discussion }\end{array}$ & $\mathrm{X} 10$ \\
\hline & & $\begin{array}{l}\text { Ability of communicate with } \\
\text { other learners }\end{array}$ & $\mathrm{X} 11$ \\
\hline & & $\begin{array}{c}\text { Efficiency of collaborative } \\
\text { learning }\end{array}$ & $\mathrm{X} 12$ \\
\hline
\end{tabular}

\section{Simulation EXPERiment And Result ANAlysis}

The evaluation of E-learning capability can provide a result of the evaluation to students and teachers, and can also help students to adjust and control their E-learning behavior, so as to achieve better learning results. According to the E-learning environment, the evaluation index system of E-learning comprehensive capability based on the AHP-BP neural network algorithm is shown in Table 1.

We set up $w$ and $L$ respectively for the weight and the underlying evaluation matrix of third level indicators, $\varphi$ and $T$ respectively for the weight and score matrix of second level indicators, and $S$ is the evaluation score of the comprehensive capability of E-learning. Due to the limited space, we only have the comprehensive evaluation of the E-learning capability for one student, and the assessment method of other students are similar to this one.

Step 1: According to $w$ and $L$, the score matrix $T$ is calculated of the second level indicators.

$$
\begin{aligned}
T_{a}=w_{a} \cdot L_{a} & =(0.435,0.323,0.242) \cdot\left[\begin{array}{ccccc}
0.2 & 0.8 & 0 & 0 & 0 \\
0 & 1 & 0 & 0 & 0 \\
0 & 1 & 0 & 0 & 0
\end{array}\right] \\
& =(0.087,0.913,0,0,0) \\
T_{b}=w_{b} \cdot L_{b} & =(0.437,0.362,0.201) \cdot\left[\begin{array}{ccccc}
0 & 0.2 & 0.6 & 0.2 & 0 \\
0 & 0.2 & 0.8 & 0 & 0 \\
0 & 0 & 1 & 0 & 0
\end{array}\right] \\
& =(0,0.1598,0.7528,0.0874,0) \\
T_{c}=w_{c} \cdot L_{c} & =(0.416,0.395,0.189) \cdot\left[\begin{array}{ccccc}
0 & 1 & 0 & 0 & 0 \\
0.2 & 0.8 & 0 & 0 & 0 \\
0 & 1 & 0 & 0 & 0
\end{array}\right] \\
& =(0.079,0.921,0,0,0) \\
T_{d}=w_{d} \cdot L_{d} & =(0.592,0.307,0.101) \cdot\left[\begin{array}{ccccc}
1 & 0 & 0 & 0 & 0 \\
0.6 & 0.4 & 0 & 0 & 0 \\
0.8 & 0.2 & 0 & 0 & 0
\end{array}\right] \\
& =(0.857,0.143,0,0,0)
\end{aligned}
$$

Step 2: According to $\varphi$ and $T$, the evaluation scores $S$ of the comprehensive capability of E-learning are calculated.

$$
\begin{aligned}
S= & \left(\varphi_{a}, \varphi_{b}, \varphi_{c}, \varphi_{d}\right) \cdot\left[T_{a}, T_{b}, T_{c}, T_{d}\right] \\
& =(0.444,0.353,0.108,0.095) \cdot\left[\begin{array}{ccccc}
0.087 & 0.913 & 0 & 0 & 0 \\
0 & 0.1598 & 0.7528 & 0.0874 & 0 \\
0.079 & 0.921 & 0 & 0 & 0 \\
0.857 & 0.143 & 0 & 0 & 0
\end{array}\right]
\end{aligned}
$$

$=(0.1285,0.5748,0.2658,0.0309,0)$

Step 3: At this point, we define the comment set:

$$
V=\left\{V_{1}, V_{2}, V_{3}, V_{4}, V_{5}\right\}=\{90,80,70,60,50\}
$$

The results of the sub indexes are calculated.

$E_{a}=V \cdot T_{a}=(90,80,70,60,50) \cdot[0.087,0.913,0,0,0]^{T}=80.87$

$E_{a}=V \cdot T_{a}=(90,80,70,60,50) \cdot[0,0.1598,0.7528,0.0874,0]^{T}=70.72$

$E_{a}=V \cdot T_{a}=(90,80,70,60,50) \cdot[0.079,0.921,0,0,0]^{T}=80.79$

$E_{a}=V \cdot T_{a}=(90,80,70,60,50) \cdot[0.857,0.143,0,0,0]^{T}=88.57$

Then, the results of the evaluation of the comprehensive capability of E-learning are calculated.

$$
F=V \cdot S=(90,80,70,60,50) \cdot[0.1285,0.5748,0.2658,0.0309,0]^{T}=78
$$

Step 4: In this way, the student's E-learning comprehensive capability can be obtained. At the same time, we give the following evaluation report, as shown in Table II. 
TABLE II.

EVALUATION REPORT FOR A STUDENT

Overall evaluation:

Through this stage of E-learning, your personal comprehensive capability is in a good level. Among them, the level of learning attitude, the use of E-learning platform and collaborative learning capability is very high. However, the capability of participation is lacking, and I hope you will be more active in participation in the future.

\begin{tabular}{|c|c|c|}
\hline Evaluating indicator & Evaluation score & Comment \\
\hline Learning attitude & 80.87 & At a higher level, I hope you continue to maintain \\
\hline Capability of active participation & 70.72 & At a moderate level, I hope you will more actively participate in the activities. \\
\hline The use of E-learning platform & 80.79 & At a higher level, I hope you continue to maintain \\
\hline Capability of cooperative learning & 88.57 & Good communication skills, I hope you take this advantage \\
\hline
\end{tabular}

Step 5: Finally, we use the BP neural network to predict the evaluation results of 1000 students, and compare them with the results obtained by the AHP method, so as to illustrate the effectiveness of the method proposed in this article. We use the E-learning comprehensive capability with 990 students as a sample of the BP neural network, so as to train the BP neural network. Then, we predict the E-learning comprehensive capability of the remaining 10 students. According to the information in section 3 , the number of input factors of the neural network is 12 , the number of the output value is 1 , and the number of the hidden layers is determined by the minimum fitting error. After multiple times of training, the final number of hidden layers is 4 , and the fitting error is 0.0412 . So, the model proposed in this paper is a BP 12-4-1 neural network. The fitting error and prediction results are given in Figure 5 and Figure 6 respectively.

Figure 6 shows that the prediction results of the BP neural network and the evaluation results obtained by the AHP method are similar. This proves the effectiveness of the AHP method on the evaluation of the E-learning comprehensive capability. At the same time, the BP neural network method can be used to deal with a large number of evaluation results, which can save time without loss of accuracy.

\section{CONCLUSION}

In this article, we first build an E-learning platform based on cloud computing, and introduce the software interface and function. Secondly, data mining technology is used to analyze and collect the record data in the process of E-learning, so as to establish the evaluation system of the E-learning comprehensive capability. Then, we propose an E-learning capability evaluation model based on an AHP-BP neural network algorithm. Finally, through experiments we can see that the prediction results of the BP neural network and the evaluation results obtained by the AHP method are similar. This proves the effectiveness of the AHP method on the evaluation of the E-learning comprehensive capability.

\section{REFERENCES}

[1] Moore. Three types of interaction[J].American Journal of Distance Education, 1989,(2):1-6.

[2] Hiltz, S.R. Online education: perspectives on a new environment.[M]. New York: Praeger, 1990: 133-184.

[3] Gunawardena. C, C.Lowe, T. Anderson. Analysis of a global online debate and the development of an interaction analysis model for examining the social construction of knowledge in computer conferencing[J].Journal of Educational Computing Research, 1997, (4): $397-431$.

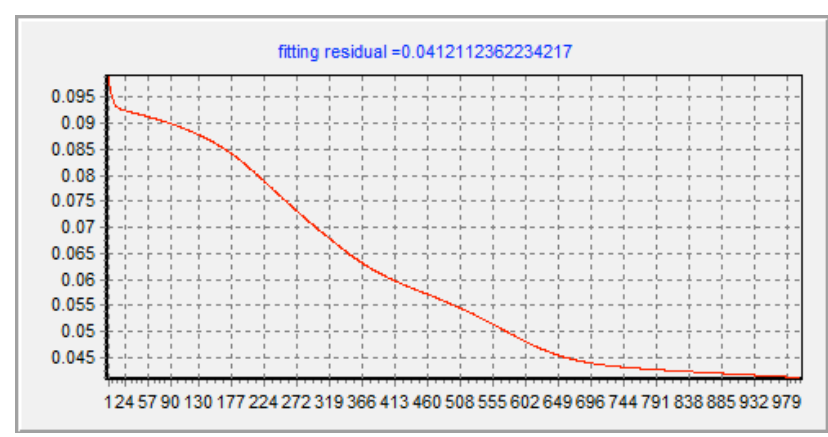

Figure 5. The number of hidden layer nodes is 4 in the neural network training $(\mathrm{N}=990)$

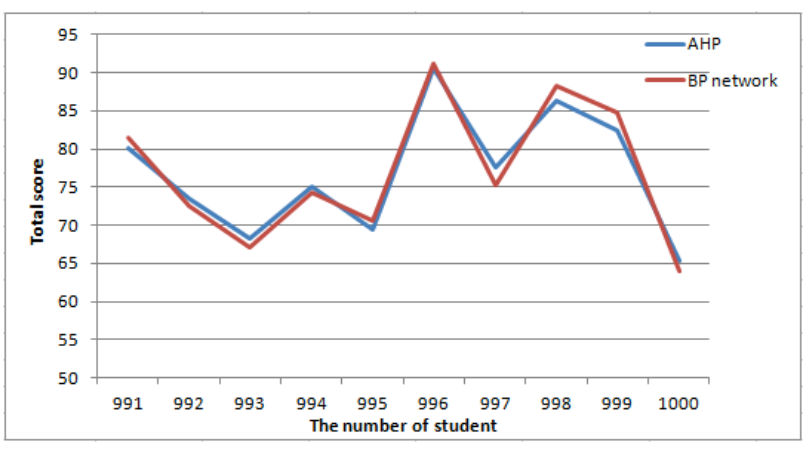

Figure 6. Comparison of prediction results

[4] Karel Kreijns, Paul A. Kirschner, Wim Jochems. The Sociability of Computer-Supported Collaborative Learning Environments[J]. Journal of Educational Technology \& Society, 2002, (1): 8-22.

[5] Chen Li, Cao Liangliang. The way and characteristics of distance learners' behavior in asynchronous interaction[J]. Distance education in china. 2006, (1): 15-19.

[6] Zhong Zhixian, Yang Lei. On Learning on Line[J]. The modern distance education. 2002, (1): 30-34.

[7] Zhong Zhixian, Yang Lei. On Learning on Line(Continued) [J]. The modern distance education. 2002, (2): 14-17.

[8] Zhong Zhixian, Yang Lei. On Learning on Line(Continued) [J]. The modern distance education. 2002, (3): 16-18.

[9] Zhong Zhixian, Yang Lei. On Learning on Line(Continued) [J]. The modern distance education. 2002, (4): 13-17.

[10] CAO Liangliang. Interaction Potential of Asynchronous Interactive Tools: Research on Instructional Interaction Structure Model in Asynchronous Interaction[J]. Open education research. 2008, 1(14):97-101.

[11] Lee Alisa, Zhang Qinglin. The types and characteristics of online learning [J]. Education Science. 2003, (1): 49-52.

[12] Zhou Yanan. The ecosystem perspective of network learning [J]. The modern distance education. 2005, (6): 41-43.

[13] Gao xingyuan. Design and implementation of the feedback function of online learning platform $[\mathrm{J}]$. Chinese education information, 2012, (21): 50-51. 
[14] Zang Lixin, Li Maolin. Research on the Virtual Classroom Management Strategies from the Perspective of Group Dynamics[J]. Journal of distance education, 2011, (6): 39-43.

[15] Li Shimei,Han Qinglan. The Research on Colleague Teacher's Comprehensive Performance Evaluation Based on AHP Model[J]. Journal of Beijing institute of education(natural science edition), 2008, 3(5): 21-27.

[16] Qiao Weide. Teaching Ability Evaluation Based on AHP Information Technology and Curriculum[J]. Changzhou Radio \&Television University, 2007, (5): 42-44.

\section{AUTHOR}

Chuanfu Hu received his M.Sc. in Computer Science (2001) from Zhejiang University. Now he is a full teacher of software engineering at the School of Computing, Dongguan University of Technology, Dongguan, 523808, Guangdong, China. (e-mail: hucf@dgut.edu.cn)

Submitted 16 July 2016. Published as resubmitted by the authors 25 August 2016. 